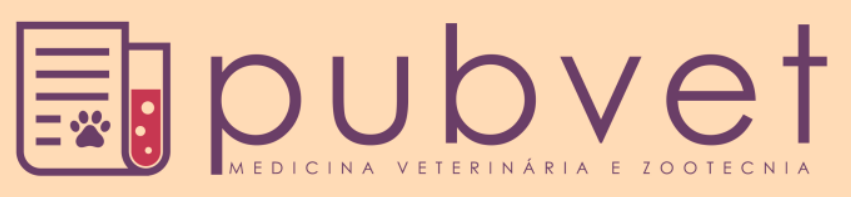

ISSN $1982-1263$

https://doi.org/10.22256/pubvet.v12n6a119.1-8

\title{
Contagem bacteriana total e contagem de células somáticas como indicadores de perdas de produção de leite
}

\author{
Alan Andrade Mesquita ${ }^{1}$, Jerry Borges ${ }^{2}$, Sandra Maria Pinto $^{3}$, Franciele de Faria \\ Lugli $^{4}{ }^{\ominus}$, Ana Carolina de Oliveira Castro ${ }^{4} \bullet$, Marina Romano De Oliveira ${ }^{4} \bullet$, Geraldo \\ Marcio da Costa ${ }^{5 *}$ \\ ${ }^{1}$ Zootecnista da Universidade Federal de Lavras, Lavras-MG Brasil.E-mail: aamzootec@yahoo.com.br \\ ${ }^{2}$ Professor Departamento de Medicina Veterinária da Universidade Federal de Lavras, Lavras-MG Brasil. E-mail: jerrycborges@yahoo.com.br \\ ${ }^{3}$ Professora Departamento de Ciências dos Alimentos da Universidade Federal de Lavras, Lavras-MG Brasil. E-mail: sandra@dca.ufla.br \\ ${ }^{4}$ Graduandas do curso de Medicina Veterinária da Universidade Federal de Lavras, Lavras-MG Brasil. \\ ${ }_{5}^{5}$ Professor Departamento de Medicina Veterinária da Universidade Federal de Lavras, Lavras-MG Brasil. E-mail: marciocostavet@gmail.com \\ *Autor para correspondência
}

\begin{abstract}
RESUMO. A mastite bovina é a doença mais relevante em bovinos leiteiros em todo o mundo, ocasionando expressivos prejuízos aos produtores, à indústria láctea e consumidores. O objetivo deste trabalho foi avaliar o impacto econômico da mastite bovina sobre a produção e economia em condições de explorações brasileiras. Para tal, foram estimados as perdas de produção de leite e os prejuízos econômicos em relação às contagens de células somáticas no leite do tanque (CCSt) e contagem bacteriana total (CBT), em rebanhos da região de Campos das Vertentes, uma importante bacia leiteira do Estado de Minas Gerais. Para se calcular as perdas de produção, utilizaram-se as médias de três CCSt, de 306 propriedades, obtidas em intervalos de 15 dias entre as coletas, sendo estimadas as perdas por meio da equação de regressão linear y= 4,7908 +0,0226x, na qual a variável " $x$ " representa a contagem de células somáticas do tanque (CCSt) e "y"a perda em \% de produção de leite. As médias de CCSt e de CBT entre as propriedades amostradas foram de 482.650 cels $/ \mathrm{mL}$ e $43.710 \mathrm{UFC} / \mathrm{mL}$ de leite, respectivamente, verificando-se que $35,6 \%$ dos estabelecimentos se encontravam acima dos limites estabelecidos pela legislação vigente para a CCSt e 7,84\% para CBT. Os resultados demonstraram que a média de produção diária nas propriedades foi de 488,43 litros de leite e que estimativas de perdas médias diárias na produção devido à mastite foram de $6,80 \%$. Não se observaram diferenças significativas quanto às perdas percentuais de produção em função da produção diária das propriedades. Os resultados obtidos evidenciam a necessidade de um controle mais efetivo da mastite, visando minimizar as perdas de produção leiteira e melhorar os índices econômicos, assim como elevar a sanidade do rebanho e a qualidade da matéria-prima ofertada.
\end{abstract}

Palavras chave: infecções intramamárias, mastite, perdas de produção, qualidade do leite, sanidade animal

\section{Total bacterial count and somatic cell count as indicators of milk production losses in dairy herds}

ABSTRACT. Bovine mastitis is the most relevant disease in dairy cattle worldwide, causing significant losses to producers, the dairy industry and consumers. The objective of this study was to evaluate the economic impact of bovine mastitis on production and economy under Brazilian farm conditions. For this, milk production and economic losses 
were estimated in relation to bulk milk somatic cell counts (BMSCC) and total bacterial counts (TBC) in herds of the mesoregion of Campos das Vertentes, an important dairy region of Minas Gerais State. In order to calculate the production losses, were calculated the means of three BMSCC of 306 dairy herds, obtained at intervals of 15 days between the collections. The losses were estimated through the linear regression equation: $\mathrm{Y}=-$ $4.7908+0.0226 x$, where the variable " $\mathrm{x}$ " represents the BMSCC, and "Y" represents the estimative of milk production losses. The mean values of BMSCC and TBC among the farms studied were 482,650 cells / $\mathrm{mL}$ and 43,710 CFU / $\mathrm{mL}$ of milk, respectively. About $35.6 \%$ and $7,84 \%$ of the establishments were above to the BMSCC and TBC limits established by the current legislation, respectively. The results showed that the average daily production in the farms was 488.43 liters of milk, and the average daily production losses due to mastitis among the farms were $6.80 \%$. No significant differences were observed regarding the production losses as a function of the milk production scores of the properties. The results obtained evidenced the need for a more effective control of mastitis, aiming to minimize losses of milk production and to improve economic indexes, as well as to increase the sanity of the herd and the quality of the raw milk produced.

Keywords: intramammary infections, mastitis, loss of production, milk quality, animal health

\section{Recuento bacteriano total y recuento de células somáticas como indicadores de pérdidas en la producción de leche}

RESUMEN. La mastitis bovina es la enfermedad más relevante en los bovinos lecheros en todo el mundo, ocasionando expresivos perjuicios a los productores, la industria láctea y los consumidores. El objetivo de este trabajo fue evaluar el impacto económico de la mastitis bovina sobre la producción y la economía en condiciones de explotaciones brasileñas. Para ello, se estimaron las pérdidas de producción de leche y los perjuicios económicos en relación a los conteos de células somáticas en la leche del tanque (CCSt) y el recuento bacteriano total (CBT), en rebaños de la región de Campos das Vertentes, una importante cuenca lechera del Estado de Minas Gerais. Para calcular las pérdidas de producción, se utilizaron las medias de tres CCSt, de 306 propiedades, obtenidas en intervalos de 15 días entre las colectas, siendo estimadas las pérdidas por medio de la ecuación de regresión lineal $\mathrm{y}=-4,7908+0,0226 x$, en la que la variable "x" representa el recuento de células somáticas del tanque (CCSt) y "y" la pérdida en\% de producción de leche. Las medias de CCSt y CBT entre las propiedades muestreadas fueron de 482.650 cels / mL y $43.710 \mathrm{UFC} / \mathrm{mL}$ de leche, respectivamente, verificándose que el 35,6\% de los establecimientos se encontraban por encima de los límites establecidos por la legislación vigente para la CCSt y, 7,84\% para CBT. Los resultados demostraron que la media de producción diaria en las propiedades fue de 488,43 litros de leche y que las estimaciones de pérdidas medias diarias en la producción debido a la mastitis fueron del $6,80 \%$. No se observaron diferencias significativas en cuanto a las pérdidas porcentuales de producción en función de la producción diaria de las propiedades. Los resultados obtenidos evidencian la necesidad de un control más efectivo de la mastitis, buscando minimizar las pérdidas de producción lechera y mejorar los índices económicos, así como elevar la sanidad del rebaño y la calidad de la materia prima ofertada.

Palabras clave: infecciones intramamarias, mastitis, pérdidas de producción, calidad de la leche, sanidad animal

\section{Introdução}

As lesões no tecido mamário causadas pela mastite reduzem a produção e secreção do leite pelas células secretoras do parênquima mamário, provocando alterações físico-químicas e microbiológicas no leite (Philpot \& Nickerson 1991). Os maiores impactos decorrente da mastite estão associados com a redução na quantidade e qualidade do leite produzido. Além disso, essa patologia causa aumentos substanciais nos custos de produção devido à substituição de matrizes, e 
também, impactos na saúde pública associadas à veiculação de agentes patogênicos e intoxicações alimentares devido ao consumo de leite contaminado sem pasteurização (Santos \& Fonseca 2007)

A mastite pode se apresentar nas formas clínica ou subclínica. A primeira apresenta sinais evidentes, como edema e aumento de temperatura do úbere, endurecimento, dor, grumos e pus no local e alterações das características do leite (Coser et al. 2012). Já a forma subclínica, apesar de não apresentar sinais visíveis de inflamação no úbere, é caracterizada pelo aumento no número de células somáticas, elevação dos teores de cloro e sódio, além da diminuição dos níveis de caseína, lactose e gordura, afetando a qualidade e o volume do leite produzido (Demeu et al. 2016; Costa et al. 2017).

A forma de apresentação subclínica favorece a disseminação da mastite nos rebanhos, além de causar uma falsa tranquilidade ao produtor em relação à inexistência de mastite em seu rebanho. Estimativas indicam que, para cada caso clínico desta enfermidade, ocorram 35 casos sub clínicos (Santos \& Fonseca 2007). De acordo com Lopes et al. (2012), a prevalência de mastite subclínica no rebanho nacional foi estimada em $40 \%$, causando perdas de $6 \%$ na produção de leite e uma menor remuneração em casos de pagamentos por qualidade.

A redução da produção leiteira em decorrência da mastite subclínica está associada com o aumento da CCS em resposta ao processo infeccioso (Tozzetti et al. 2008). As células somáticas compostas por leucócitos, que migram do sangue para o interior da glândula mamária, com o objetivo de combater os agentes causadores da mastite, e também por células de descamação do epitélio glandular (Philpot \& Nickerson 1991).

Outro ponto que se deve destacar em relação à qualidade do leite corresponde à contagem bacteriana total (CBT), a qual mede a microbiota do leite, que depende da carga bacteriana inicial e da taxa de multiplicação dos microrganismos, além de avaliação da higiene de ordenha e das condições de estocagem e transporte do leite cru, sendo uma importante ferramenta no controle da qualidade da matéria-prima, permitindo inferir sobre os prováveis efeitos indesejáveis acerca do rendimento industrial de produtos lácteos. Além disso, o leite com elevada CBT representa risco para a saúde do consumidor, pelo potencial de veiculação de micro-organismos e toxinas microbianas resistentes à pasteurização (Vargas et al. 2014).

Estudos prévios avaliaram a importância econômica da mastite (Saeki et al. 2011; Lopes et al. 2012; Brito et al. 2014). No entanto, há ainda poucos estudos sobre os impactos econômicos da mastite em condições de exploração brasileiras. Desta forma, no presente trabalho, foram estimadas, em função dos escores se de células somáticas no leite do tanque, as perdas de produção de leite e os prejuízos econômicos decorrentes da mastite em propriedades leiteiras da região do Campo das Vertentes, Minas Gerias.

\section{Material e Métodos}

No presente estudo foram analisadas 306 propriedades rurais produtoras de leite, localizadas na bacia leiteira da região de Campos das Vertentes, Minas Gerais. As propriedades integrantes do estudo eram vinculadas a um laticínio da região e ocupavam uma área aproximada $12.564 \mathrm{~km} 2$, tendo um efetivo bovino estimado em 34.000 animais (FAEMG, 2006). Não foram aplicados critérios probabilísticos para a escolha das propriedades estudadas, sendo a inclusão das mesmas feitas com base no relacionamento prévio dos proprietários com um laticínio e a unidade de pesquisa.

Amostras de aproximadamente $40 \mathrm{~mL}$ de leite foram coletadas diretamente no tanque de expansão, de cada propriedade após homogeneização, realizadas com coletores esterilizados. Estas após serem coletadas foram mantidas em frascos individuas estéreis, em recipientes térmicos a $4^{\circ} \mathrm{C}$ até envio aos laboratórios integrantes de Rede Brasileira de Qualidade do Leite para realização da contagem de células somáticas do tanque (CCSt) e contagem bacteriana total (CBT).

Foram realizadas três análises de CCSt e CBT em cada propriedade, em intervalos de 15 dias, no período entre março e abril de 2017. Os valores de produção diária de leite em cada propriedade no período experimental foram obtidos junto ao laticínio que captou o leite produzido.

Após calcular a média da CCSt das três coletas realizadas nas propriedades amostradas, as perdas em \% na produção de leite causadas pela mastite foram estimadas por meio da equação de regressão linear proposta pelo National Mastitis Council (NMC) (Nickerson et al. 1995).

$$
Y=-4,7908+0,0226 x \text {. }
$$


onde:

"y" representa a percentagem de perda na produção de leite;

" $\mathrm{x}$ " indica a quantidade de células somáticas no tanque (CCSt).

Após os cálculos das perdas percentuais na produção de leite, estas foram convertidas em perdas quantitativas diárias de leite (PR), para cada produtor, através do cálculo da diferença entre a produção diária sem perdas devido a CCSt e a real produção diária da propriedade. A seguir, foram avaliadas as perdas anuais em litros de leite e impacto econômico anual.

Para análise dos prejuízos econômicos, as perdas quantitativas de leite foram multiplicadas pelo valor do leite pago, através da formula seguinte:

Prejuízos econômicos $=($ Dias $\mathrm{x}(\mathrm{PR}) \mathrm{x}$ (preço L/leite)

Onde:

$\mathrm{PR}=$ Perda diária de leite estimada para cada produtor;

Dias = período de tempo avaliado;

Preço L/leite = preço pago para a venda do leite.

Os valores pagos pelo leite foram obtidos por avaliações realizadas pelo Centro de Estudos Avançados em Economia Aplicada (CEPEA) Leite - ESALQ - USP em 06 de junho de 2017.

Para avaliar se o volume da produção diária estava influenciando nas perdas analisadas através de CCSt, as propriedades foram agrupadas da seguinte forma: produtores que fornecem diariamente menos de $100 \mathrm{~L}$; produtores que fornecem entre 101 e $500 \mathrm{~L}$; produtores que fornecem entre $500 \mathrm{~L}$ e $1000 \mathrm{~L}$; e propriedades que fornecem acima de $1000 \mathrm{~L}$, diariamente;

As perdas médias de produção e as estimativas de perdas econômicas anuais foram calculadas de forma descritiva. Fez-se a comparação entre as médias dos agrupamentos das produções das propriedades para CCSt, CBT e \% de perdas correlacionadas com CCSt, pelo teste de Análise de Variância, com um nível de significância de $5 \%$. Também foi calculada a correlação de Pearson entre as variáveis CCSt e CBT. As análises estatísticas foram realizadas utilizando-se o programa estatístico SPSS $20.0^{\circledR}$.

\section{Resultados e Discussão}

A produção diária média de 548 litros verificada entre as propriedades (Tabela 1) foi superior à média nacional que é de 52 litros/dia e também acima da média do Estado de Minas Gerais, que foi estimada em 184 litros/dia (ANUALPEC 2017), mas próxima dos resultados encontrados por Pereira et al. (2016), que verificaram produção média diária de leite de 770 $\pm 697 \mathrm{~L} / \mathrm{dia}$, em propriedades no Estado de Minas Gerais. Segundo estes autores, a baixa média de produção diária pode ser reflexo da metodologia censitária utilizada pelo IBGE (2006), que inclui fazendas de gado de corte que comercializam algum excedente de leite dos bezerros, o que pode não traduzir a realidade das fazendas leiteiras, sendo que os resultados neste estudo corroboram para esta teoria.

$\mathrm{Na}$ avaliação da perda de produção devido a CCSt (Tabela 1) observou-se uma perda média de $6,27 \%$ na produção total nas propriedades estudadas, e ao se comparar os diversos estratos de produção, não foram observadas diferenças estatísticas entre eles $(\mathrm{P}>0,05)$, demonstrando que os níveis de perdas de produção são semelhantes nos diferentes estratos de produção. Estes resultados corroboram os obtidos por Magalhães et al. (2006), os quais observaram perdas de 1,02 a $21,15 \%$, correspondentes a CCSt entre 171.000 e 2.488 .000 cels $/ \mathrm{mL}$. Segundo Costa et al. (2017), à medida que a CCS é reduzida, a produção de leite aumenta, em razão da menor incidência de lesões nos tecidos do úbere.

Tabela 1. Contagens de células somáticas no leite do tanque (CCSt) e contagem bacteriana total (CBT) e estimativas de perdas de produção de leite entre produtores amostrados em função dos escores de produção

\begin{tabular}{lccccc}
\hline Produção diária & $\mathrm{N}$ & Média (L) & $\begin{array}{c}\text { CCStx1000 } \\
\text { cels/mL }\end{array}$ & $\begin{array}{c}\text { CBTx1000 } \\
\text { UFC/mL }\end{array}$ & $\begin{array}{c}\text { Estimativas de perdas de } \\
\text { produção }(\%)\end{array}$ \\
\hline$\leq 100 \mathrm{~L}$ & 60 & 63,25 & 453,83 & 41,22 & 5,71 \\
$101-500 \mathrm{~L}$ & 162 & 242,11 & 485,88 & 46,16 & 6,36 \\
$501-1000 \mathrm{~L}$ & 44 & 664,74 & 501,54 & 43,19 & 6,59 \\
$>1001 \mathrm{~L}$ & 40 & 1966,81 & 489,84 & 35,93 & 6,39 \\
Todos os produtores & 306 & 548,00 & 482,65 & 41,62 & 6,27 \\
\hline
\end{tabular}

Não se observaram diferenças estatísticas entre as médias de CCSt, CBT e estimativas de perdas de produção pelo teste de ANOVA $(p>0,05)$. 
Pereira et al. (2010) avaliaram as perdas de produção em 12 rebanhos com um número médio de 30 vacas em lactação e uma produção mínima de $7 \mathrm{~kg} / \mathrm{vaca} / \mathrm{dia}$, tendo verificado, em função das CCS individual, que as perdas de produção devido à mastite foram da ordem de 7,6\%. Estes resultados foram próximos aos encontrados no presente estudo. Este mesmo autor após o levantamento das perdas de produção, implementou um programa de controle estratégico para redução da CCS, verificando que seis meses após a implantação do mesmo as perdas foram reduzidas para $3,1 \%$, demonstrando com isso o retorno econômico decorrente do controle da mastite nos rebanhos.

Bueno et al. (2002) estimaram o percentual de redução na produção pelo somatório dos produtos entre o percentual de quartos afetados, e valores de redução na produção, em rebanhos leiteiros da região de Pirassununga, SP, os quais encontraram um percentual de redução que variou entre $3,82 \%$ e $10,79 \%$, resultados estes próximos dos encontrados neste estudo.

A média da CCSt entre todas as propriedades amostradas foi de $482.650 \mathrm{cels} / \mathrm{mL}$ de leite (Tabela 1), demonstrando que, na média, o leite captado pelo laticínio está em conformidade com a legislação vigente, a Instrução Normativa (IN) 07 do Ministério da Agricultura (Brasil, 2016), que regulamenta um máximo de 500.000 cels $/ \mathrm{mL}$ de leite. No entanto, estes escores de CCSt ainda se encontram muito aquém daqueles aceitos no mercado internacional, sobretudo na União Europeia, onde os limites máximos são inferiores a 400.000 cels. $/ \mathrm{mL}$, mas com tendências a diminuir nos próximos anos, já que nos países escandinavos e Austrália, a média nacional de CCSt foi de 200.000 a 250.000 cels $/ \mathrm{mL}$ (More 2009). Outro aspecto importante é que CCSt acima de 200.000 cels $/ \mathrm{mL}$ já é indicativo de perdas de produção e na qualidade do leite, indicando mastite subclínica em níveis elevados no rebanho (Barbosa et al. 2002; Coldebella et al. 2004; Magalhães et al. 2006). De acordo com Silva et al. (2010) altos índices de CCSt causam inúmeros prejuízos às indústrias de laticínios por afetarem de forma direta a composição do leite, reduzindo o rendimento industrial e o tempo de vida de prateleira do leite e seus derivados.

Para a variável CBT pode-se observar que todos os estratos de produção (Tabela 1) estavam dentro dos limites estabelecidos pela IN 07, que determina que a contagem máxima seja inferior a
$300.000 \mathrm{UFC} / \mathrm{mL}$ de leite. Estes resultados traduzem o esforço do laticínio por parte de sua equipe de assistência técnica aos produtores, sendo corroborados pelos resultados de Brito et al. (2007) que relataram a redução imediata de CTB de 883.000 para $74.000 \mathrm{UFC} / \mathrm{mL}$ em trabalho realizado em diferentes regiões brasileiras (Pernambuco, Sergipe, Alagoas, Minas Gerais, Goiás, São Paulo e Rio Grande do Sul), depois de serem implantadas medidas básicas de higiene da ordenha e limpeza dos utensílios. No entanto, se contrapõem àqueles obtidos por Souza et al. (2009) que verificaram uma média para CBT de $892.000 \mathrm{UFC} / \mathrm{mL}$ em rebanhos localizados em Minas Gerais, Rio de Janeiro e Espírito Santo.

Nossos resultados apontaram que 2,6\% das propriedades analisadas ainda se encontravam acima do limite de $300.000 \mathrm{UFC} / \mathrm{mL}$ e que $35,6 \%$ dos produtores estavam fora dos parâmetros legais para CCSt. Estes produtores além de terem perdas de produção também prejudicam os laticínios que adquirem este leite de qualidade inferior. Leites com alta CCSt apresentam aumento da atividade proteolítica, decorrente principalmente da atividade da plasmina. Ocorre ainda que o leite proveniente de vacas com mastite apresenta menor teor de caseína devido à redução da sua síntese e à ocorrência de proteólise, comprometendo o rendimento do leite usado na fabricação de queijos e outros lácteos derivados (Andrade 2008).

$\mathrm{Na}$ Tabela 2, pode-se observar as médias de CCSt das propriedades que não estavam em conformidade com a legislação vigente de acordo com os estratos de produção. As contagens médias foram bastante elevadas nos diferentes estratos, verificando-se que 107 produtores estavam em inconformidade com este quesito, correspondendo a $35,6 \%$ das propriedades amostradas. Estes resultados foram similares aos encontrados por Souza et al. (2009) que ao avaliarem as características e práticas de manejo associadas à CCSt em 175 rebanhos leiteiros, observaram que $51 \%$ dos rebanhos apresentavam contagens acima de 500.000 cels $/ \mathrm{mL}$ de leite.

Pode-se observar pelos dados da Tabela 3 que apenas $15,35 \%$ das propriedades apresentavam $\mathrm{CBT} \geq 100.000 \mathrm{UFC} / \mathrm{mL}$. No entanto, somente $2,61 \%$ das mesmas estavam em inconformidade com a IN 07, que estabelece contagens inferiores a $300.00 \mathrm{UFC} / \mathrm{mL}$ para o leite do tanque. Nestas propriedades (CBT $\geq 100.000 \mathrm{UFC} / \mathrm{mL}$ ), as CCSt eram mais elevadas, demonstrando existir correlação entre as variáveis $(r=0,63)$. Este 
resultado é corroborado por Lopes Júnior et al. (2012) que verificaram uma correlação entre CCS e CTB maior que 0,60. A correlação entre CCSt e CBT verificada em nosso estudo, ainda que de baixa intensidade, demonstra que existe a associação entre o fenômeno inflamatório da glândula mamária, indicado pelos escores de CCSt, e a eliminação de bactérias no leite em decorrência da mastite. Outra possível explanação para esta associação seria a existência de fatores determinantes comuns para o incremento dos níveis de mastite no rebanho e, consequentemente da CCSt, e o aumento da CBT. Um destes fatores poderia ser a falha de higiene na ordenha (falhas na limpeza de equipamentos de ordenha; uso de água de má qualidade microbiológica nos processos de limpeza e desinfecção; falhas na antisepsia de tetos, dentre outros).

Segundo Vargas et al. (2014), a elevação da CBT pode ser ocasionada pela contaminação tanto por utensílios que entram em contato com o leite, pele de tetos e úbere, como pela glândula mamária infectada, principalmente por estreptococos causadores de mastite subclínica, o que, explicaria o aumento simultâneo da CBT e CCSt. Também no estudo realizado por Almeida et al. (2015) verificarame que nas mastites ocasionadas por bactérias do gênero Streptococcus houve um incremento na contagem bacteriana dos quartos afetados significativamente maior em relação às contagens observadas nos quartos afetados por Staphylococcus ou por Corynebacterium.
O impacto da mastite na produção, estimado por meio da CCSt, teve uma relevância significativa nas propriedades estudadas, visto que na média os produtores perderam anualmente 8.884 litros de leite, o que representou perdas anuais de 2.718.581,64 de litros, equivalentes a $\mathrm{R} \$$ 3.833.200,11 de acordo com os preços pagos pelo laticínio em junho de 2017 (Tabela 4). No estrato de maior produção (>1001 L/dia), que responde por $52,1 \%$ da produção captada pelo laticínio, as perdas de produção foram estimadas em $1.317 .579,60$, o que corresponde a $\mathrm{R} \$$ $1.857 .787,24$.

Os resultados do nosso estudo apontaram uma estimativa de perdas de $\mathrm{R} \$ 0,083$ para cada litro de leite produzido. No estudo realizado por Lopes et al. (2012) no qual estimou-se que o impacto econômico anual da mastite, tomando por referência uma vaca em lactação, foram estimadas perdas anuais médias de $\mathrm{R} \$ 0,2146$ e de $\mathrm{R} \$$ $0,4311 / \mathrm{kg}$ de leite produzido para os escores de CCSt de 250.000 e 1.000 .000 de céls./mL de leite, respectivamente. Esta diferença, em relação ao nosso estudo, pode estar relacionada com a metodologia utilizada pelos autores supracitados, na qual se contabilizaram, no cálculo do impacto econômico, os custos com medidas preventivas e terapêuticas, incluindo o descarte de vacas cronicamente acometidas, descarte de leite, além do total em perdas na produção em decorrência da queda de produção.

Tabela 2. Contagens de células somáticas no leite do tanque (CCSt) e contagem bacteriana total (CBT) em propriedades que apresentavam CCSt superior a $500.000 \mathrm{cels} / \mathrm{mL}$, em função dos extratos de produção

\begin{tabular}{lcccc}
\hline Produção diária & $\mathrm{N}$ & Média (L) & $\begin{array}{c}\text { CCSt x1000 } \\
(\text { cels } / \mathrm{mL})\end{array}$ & $\begin{array}{c}\text { CBT x1000 } \\
(\text { UFC/mL) }\end{array}$ \\
\hline$\leq 100 \mathrm{~L}$ & 17 & 66 & 839 & 82 \\
$101-500 \mathrm{~L}$ & 62 & 266 & 777 & 65 \\
$501-1000 \mathrm{~L}$ & 14 & 576 & 911 & 105 \\
$>1001 \mathrm{~L}$ & 14 & 1671 & 801 & 37 \\
Total dos produtores com CCSt $>500.000$ & 107 & 456 & 806 & 69 \\
\hline
\end{tabular}

Tabela 3. Contagem bacteriana total (CBT) e contagens de células somáticas no leite do tanque (CCSt) em propriedades que apresentavam CBT superiores a $100.000 \mathrm{UFC} / \mathrm{mL}$, em função dos estratos de produção

\begin{tabular}{lcccc}
\hline Produção diária & \multirow{2}{*}{$\mathrm{N}$} & \multirow{2}{*}{ Média (L) } & $\begin{array}{c}\text { Média de CBT X 1000 Média de CCSt X 1000 } \\
\text { UFC/mL }\end{array}$ & 694 \\
\hline$\leq 100 \mathrm{~L}$ & 5 & 55 & 259 & 849 \\
$101-500 \mathrm{~L}$ & 14 & 256 & 278 & 1382 \\
$501-1000 \mathrm{~L}$ & 2 & 534 & 507 & 482 \\
$>1001 \mathrm{~L}$ & 2 & 3232 & 256 & 819 \\
Total dos produtores com CBT $>100.000$ & 24 & 495 & 285 & \\
UFC/mL & & & \\
\hline
\end{tabular}


Tabela 4. Estimativas anuais de perdas econômicas e de produção de leite em função dos estratos de produção

\begin{tabular}{lccccc}
\hline $\begin{array}{l}\text { Produção diária } \\
\text { (L/dia) }\end{array}$ & $\mathrm{N}$ & $\begin{array}{c}\text { Produção estimada } \\
\text { anual }\end{array}$ & $\begin{array}{c}\text { Produção corrigida } \\
\text { CCST <200.000 cels/mL }\end{array}$ & $\begin{array}{c}\text { Perdas de leite devido } \\
\text { a CCSt (L) }\end{array}$ & Perdas (R\$) \\
\hline$<100$ & 60 & $1.157 .514,60$ & $1.221 .438,60$ & $63.924,00$ & $90.132,84$ \\
$101-500$ & 162 & $11.962 .463,94$ & $12.767 .898,78$ & $805.434,84$ & $1.135 .663,12$ \\
$501-1000$ & 44 & $8.920 .807,28$ & $9.452 .450,48$ & $531.643,20$ & $749.616,91$ \\
$>1001$ & 40 & $23.995 .028,40$ & $25.312 .608,00$ & $1.317 .579,60$ & $1.857 .787,24$ \\
$\begin{array}{l}\text { Todos os } \\
\text { produtores }\end{array}$ & 306 & $46.035 .814,22$ & $48.754 .395,86$ & $2.718 .581,64$ & $3.833 .200,11$ \\
\hline
\end{tabular}

É importante salientar que a mastite além de causar perdas para o produtor em função de menor produção dos animais afetados, gastos com medicação, descarte de leite de animais em tratamento, descarte e óbitos eventuais de animais e os custos inerentes às medidas de controle, causa perdas para a indústria, em função das alterações na composição do produto, representadas principalmente pela diminuição dos teores de caseína e gordura, e diminuição da vida de prateleira dos produtos. Tais fatos, demonstram a necessidade de um controle mais efetivo da mastite nos rebanhos da região estudada, não somente visando proporcionar maior renda para os produtores, mas também à oferta de matéria-prima de melhor qualidade para os laticínios. Estudos prévios demonstraram a viabilidade econômica da adoção destas práticas. Em um destes estudos, Lopes et al. (2012) verificaram que as despesas com as medidas preventivas para a mastite representaram, no máximo, $19,7 \%$ dos custos totais relativos ao impacto econômico da doença, o que demonstra vantagens em

\section{Conclusões}

Conclui-se que, em função dos escores de CCSt, que os produtores têm uma perda média de $6,27 \%$ de sua produção diária de leite, o que resulta em um impacto econômico negativo anual elevado. Os escores médios de CCSt verificados, embora próximos dos limites legais, demonstram a necessidade de um controle mais efetivo da mastite, pois uma parcela considerável dos produtores ainda se encontra acima dos limites permitidos pela legislação vigente.

Considerando-se a importância econômica e de saúde pública da mastite bovina, torna-se indispensável à proposição estratégias de controle para a doença que sejam de baixo custo, atendendo assim aos interesses dos produtores em melhorar a produtividade e a rentabilidade de seus sistemas de produção, bem como atendendo às demandas dos laticínios por matéria prima de melhor qualidade e maior rendimento industrial, maior vida de prateleira, melhor qualidade dos produtos, e dos consumidores quanto à qualidade e segurança alimentar.

\section{Referências bibliográficas}

Almeida L.A.B., Brito M.A.V.P., Brito J.R.F., Pires F.A. \& Benites N.R. 2015. Tratamento de mastite clínica experimental por meio de ordenhas múltiplas em vacas leiteiras inoculadas com Staphylococcus aureus. Arquivo Instituto Biológico 72, 1-6.

Andrade S.F. 2008. Manual da Terapêutica Veterinária. Rocca, São Paulo.

ANUALPEC 2017. Anuário da Pecuária Brasileira. Instituto FNP, São Paulo, SP, Brasil.

Barbosa C.P., Benedetti E., Ribeiro S.C.A. \& Guimaraes E.C. 2002. Relação entre contagem de células somáticas (CCS. e os resultados do "California Mastitis Test"(CMT), no diagnóstico de mastite bovina. Bioscience Journal 18, 93-102.

Brasil. Ministério Da Agricultura, Pecuária e Abastecimento. Instrução Normativa 07 de 03 de maio de 2016. Dispõe sobre alterações no regulamento técnicos de produção, identidade, qualidade, coleta e transporte do leite. Diário Oficial da União, Brasília, Seção 1, 84 maio. 2016.

Brito D.A.P., Silva I.d.S.O., Brito D.R.B. \& Costa F.N. 2014. Prevalência e etiologia da mastite em bovinos leiteiros da Ilha de São Luís, estado do Maranhão, Brasil. Brazilian Journal of Veterinary Medicine 36, 389-95.

Brito J.R.F., Brito M.A.V.P.E., Souza G.N., Moraes L.C.D., Arcuri E.F., Lange C.C. \& Diniz F.H. 2007. Avaliação da eficiência do "Kit Embrapa Ordenha Manual" para melhorar a qualidade microbiológica do leite em pequenas propriedades de quatro regiões brasileiras. In: Congresso Internacional do Leite. EMBRAPA, Resende, Minas Gerais.

Bueno V.F.F., Nicolau E.S., Mesquita A.J., Ribeiro A.R., Silva J.A.B., Costa E.O., Coelho K.O. \& Neves R.B.S. 2002. Mastite bovina clínica e subclínica, na região de Pirassununga, SP: 
frequências e redução na produção. Ciência Animal Brasileira 4, 47-52.

Coldebella A., Machado P.F., Demétrio C.G.B., Ribeiro Júnior P.J., Meyer P.M., Corassin C.H. \& Cassoli L.D. 2004. Contagem de células somáticas e produção de leite em vacas holandesas confinadas. Revista Brasileira de Zootecnia 33, 623-34.

Coser S.M., Lopes M.A. \& Costa G.M. 2012. Mastite bovina: controle e prevenção. Boletim Técnico 93, 1-30.

Costa H.N., Molina L.R., Lage C.F.A., Malacco V.M.R., Facury Filho E.J. \& Carvalho A.Ú. 2017. Estimativa das perdas de produção leiteira em vacas mestiças Holandês x Zebu com mastite subclínica baseada em duas metodologias de análise. Arquivo Brasileiro de Medicina Veterinária e Zootecnia 69, 579-86.

Demeu F.A., Lopes M.A., Costa G.M., Rocha C.M.B.M. \& Santos G. 2016. Efeito da produtividade diária de leite no impacto econômico da mastite em rebanhos bovinos. Boletim de Indústria Animal 73, 53-61.

Federação de Agricultura do Estado de Minas Gerais - FAEMG 2006. Diagnóstico da pecuária leiteira do estado de Minas Gerais em 2005: relatório de pesquisa. Belo Horizonte, 156p.

IBGE, 2006. Censo Agropecuário 2006, Brasilia. Available at: http://www.ibge.gov.br/.

Lopes Júnior, J.E.F., Ferreira J.E., Lange C.C., Brito M.A.V.P., Santos F.R., Silva M.A.S., Moraes L.C.D. \& Souza G.N. 2012. Relationship between total bacteria counts and somatic cell counts from mammary quarters infected by mastitis pathogens. Ciência Rural 42, 691-6.

Lopes M.A., Demeu F.A., Rocha C.M.B.M., Costa G.M., Franco Neto A. \& Santos G. 2012. Avaliação do impacto econômico da mastite em rebanhos bovinos leiteiros. Arquivos do Instituto Biológico 79, 477-83.

Magalhães H.R., El Faro L., Cardoso V.L., Paz C.C.P., Cassoli L.D. \& Machado P.F. 2006. Influência de fatores de ambiente sobre a contagem de células somáticas e sua relação com perdas na produção de leite de vacas da raça Holandesa. Revista Brasileira de Zootecnia 35, 415-21.

More S.J. 2009. Global trends in milk quality: implications for the Irish dairy industry. Irish Veterinary Journal 62, 5-14.
Nickerson S., Owens W. \& Boddie R. 1995. Mastitis in dairy heifers: initial studies on prevalence and control. Journal of Dairy Science 78, 1607-18.

Pereira E.S., Pimentel P.G., Queiroz A.C. \& Mizubuti I.Y. 2010. Novilhas leiteiras. Graphiti Gráfica e Editora Ltda, Fortaleza, Ceará.

Pereira M.N., Resende J.C., Pereira R.A.N. \& Silva H.C.M. 2016. Indicadores de desempenho de fazendas leiteiras de Minas Gerais. Arquivo Brasileiro de Medicina Veterinária e Zootecnia 68, 1033-42.

Philpot W.N. \& Nickerson S.C. 1991. Mastitis: counter attack.

Saeki E.K., Mello Peixoto E.C.T., Matsumoto L.S., Marcusso P.F. \& Monteiro R.M. 2011. Mastite bovina por Staphylococcus aureus: sensibilidade às drogas antimicrobianas e ao extrato alcoólico de própolis. Acta Veterinaria Brasilica 5, 284-90.

Santos M.V. \& Fonseca L.F.L. 2007. Estratégias para controle de mastite e melhoria da qualidade do leite. Manole, São Paulo, Brasil.

Silva M.V.M., Nogueira J.L., Passos C.C., Ferreira A.O. \& Ambrósio C.E. 2010. A mastite interferindo no padrão de qualidade do leite: uma preocupação necessária. Revista científica eletrônica de medicina veterinária 3, 1-10.

Souza G.N., Brito J.R.F., Moreira E.C., Brito M.A.V.P. \& Silva M.V.G.B. 2009. Variação da contagem de células somáticas em vacas leiteiras de acordo com patógenos da mastite Somatic cell counts variation in dairy cows according to mastitis pathogens. Arquivo Brasileiro de Medicina Veterinária e Zootecnia 61, 1015-20.

Tozzetti D.S., Bataier M.B.N., Almeida L.R. \& Piccinin A. 2008. Prevenção, controle e tratamento das mastites bovinas-revisão de literatura. Revista científica eletrônica de medicina veterinária 6, 1-7.

Vargas D.P., Nörnberg J.L., Mello R.O., Sheibler R.B., Milani M.P. \& Mello F.C.B. 2014. Correlações entre contagem bacteriana total e parâmetros de qualidade do leite. Revista Brasileira de Ciência Veterinária 20, 241-7.

Article History:

Received 1 March 2018

Accepted 29 March 2018

Available online 6 June 2018

License information: This is an open-access article distributed under the terms of the Creative Commons Attribution License 4.0, which permits unrestricted use, distribution, and reproduction in any medium, provided the original work is properly cited. 